\title{
APPLICATION OF THE GROSS ERROR ANALYSIS TO DISORDERS IDENTIFICATION IN MANUFACTURING PROCESS-A CASE STUDY
}

Izabela Dagmara Czabak-Górska ${ }^{1}$, Aneta Kucińska-Landwójtowicz ${ }^{2}$

\begin{abstract}
The article contains a description of the procedures to be followed in the analysis of the stability of the manufacturing processes based on an Individual Control Chart (XI) and a Moving Range (MR) Control Chart. In the following part of the article, we present the three-sigma rule and the confidence intervals for the average, which enable the elimination of random errors caused by, e.g. an improper conducting of a measurement.

Summary of the theoretical considerations is a study case in which survey data from a company, producing car seat frames, are used. The conducted study indicates that the elimination of Gross Error is significant to identify and eliminate the variability of production processes.
\end{abstract}

UDC Classification: 338.3, DOI: http://dx.doi.org/10.12955/cbup.v3.597

Keywords: stability of the process, Individuals Control Chart (IX), Moving Range Control Chart (MR), elimination of Gross Error, Statistical Process Control (SPC)

\section{Introduction}

The stability analysis of manufacturing processes is a key aspect of the continuous improvement of the product quality. Modern companies strive for perfect quality of offered products in order to maintain or strengthen its market position. This requires a permanent control and process steering at various production stages. Thanks to such an approach, it is possible to prevent, among others, the generation of costs associated with removal of the resulting defects or defective products (already at the manufacturing stage).

For the process analysis being used in the Statistical Process Control (SPC), in which the main task is to capture the results (at various stages of production), it is significantly distinctive from the rest of the measurements conducted. John Oakland (Oakland, 2007) emphasized that the SPC is not merely a collection of tools, but it is a strategy that allows the identification and elimination of the volatility present in such processes, e.g. production. According to Jensen (2006), the control charts are the most effective and common tool, serving the steering and monitoring of the processes.

Thompson, Koronacki, \& Nieckuła (2005) discerned three key stages of the Statistical Process Control:

- Finding of a signal that proves the deregulation of the production process (abnormal measurement),

- identification of the source of the revealed deregulation,

- improvement of the process quality based on the conclusions from the conducted analysis.

The unusual signals, appearing in the process, may eventually indicate the direction of corrective actions, which should be implemented in order to improve its quality.

In this article, we propose a procedure during the analysis of signs appearing on a Control Chart, which provides proof of disorders concerning the manufacturing process based on the Gross Errors analysis, which can be used in practice by a preliminary analysis of the reasons for the appearance of unusual behavior of the process. Additionally, we base our considerations on a case study, which is an extension of the research, conducted by Lorenc \& Czabak-Górska (2014), concerning the process stability analysis.

\footnotetext{
${ }^{1}$ Izabela Dagmara Czabak-Górska, M. Sc., Faculty of Production and Logistics Engineering, Department of Production and Services Quality Engineering, Opole University of Technology, i.gorska@po.opole.pl

2 Aneta Kucińska-Landwójtowicz, D. Sc., Faculty of Production and Logistics Engineering, Department of Production and Services Quality Engineering, Opole University of Technology, a.kucinska@po.opole.pl
} 


\section{Individuals and Moving Range Control Chart}

In the case of study, we used an Individual (XI) and Moving Range (MR) Contol Chart, which allow detecting of so called "special causes variation." The cause of their occurrence can be the Gross Error in the measurements data. Calculation of Control Limits and more information about this Control Charts can be found in various research works, e.g. Oakland (2003) and Greber (2000).

Greber (2000) explained that the use of control charts is based on the identification of the researched characteristics and gathering samples at specified intervals. It is one of the methods of Process Control "online," which takes place in real time. Such an approach enables the up-to-date detection of all the disturbing signals regarding changes taking place in the process (for each of its stages). This could possibly become a prerequisite for suggesting the need of making a decision about its stoppage at the moment of the appearance of too many deviations. In the analysis of Control Charts, the cause of all (even those single) signals about changes taking place in the production process is to be explained.

\section{The importance of Gross Errors elimination from the manufacturing process}

Narasimhan \& Jordache (2000) noted that the identification and elimination of Gross Errors is very important in the proper analysis of the measurement data, especially in the areas, the control of the process, online optimization, and process economic evaluation. This aspect is also crucial from the point of view of the proper inferences concerning the production process based on real data, e.g. in the Six Sigma methodology.

The undoubted disadvantage of such an approach is the failure to obtain a clear answer to the question: "What has contributed to the emergence of the disruption signal in the process?" The presented method only allows for the conclusion that the selected samples are just random errors caused mostly by improperly executed measurements.

\section{Gross Error elimination method-three-sigma rule and confidence ranges for the average}

One of the methods of the Gross Errors analysis is the three sigma rule, which has been described, among many, by Aczel (2013) and Lehmann (2013) (other methods are described, for example, by Narasimhan \& Jordache (2000), Yang, Ten, \& Yao (1995), etc.). The authors decided to apply this technique due to the natural volatility the process ranges in, according to the classical approach of conducting Control Charts proposed by the Shewhart (1931). In practice, it means that $99.73 \%$ of the observations are within the specification limits (Figure 1).

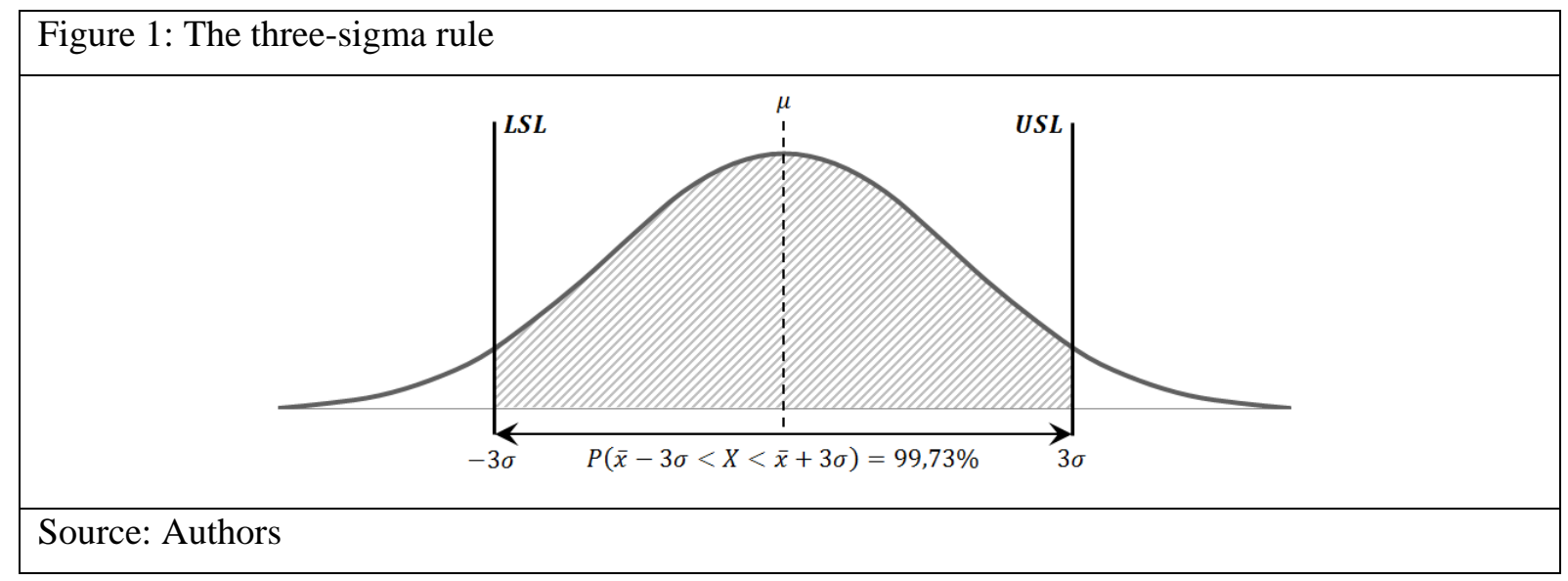

The three-sigma rule only enables the identification of Gross Errors in a series of measurements-a decision as to whether to reject them still remains. It should be justified by an appropriate statistical 
test. In this case, the confidence range for the average (in the case of a large sample - $n \geq 30$ ) should be used:

$$
\mathrm{P}\left(\overline{\mathrm{x}}_{\mathrm{o}}-\mathrm{u}_{\alpha} \cdot \frac{\mathrm{s}_{\mathrm{o}}}{\sqrt{n}} \leq \mu \leq \overline{\mathrm{x}}_{\mathrm{o}}+\mathrm{u}_{\alpha} \cdot \frac{\mathrm{s}_{\mathrm{o}}}{\sqrt{n}}\right)=1-\alpha,
$$

where:

$\overline{x_{o}}$ - the arithmetic average determined after the rejection of the Gross Error,

$s_{o}$ - standard deviation (of a sample) after discarding the Gross Error,

$u_{\alpha}$-value of the normal cumulative distribution function $\mathrm{N}(0,1)$ for the level of significance $\alpha$,

$\alpha$ - level of significance,

$1-\alpha$ - level of confidence.

The result should be rejected if it is placed outside the values of the described confidence range (1).

\section{The case study}

Examination of the process stability, using an Individual (IX) and the Moving Range (MR), was performed in a company producing car seat frames. Samples were taken in accordance with internal procedures (separately for each measurement) for six consecutive days. Table 1 summarizes the main steps of the process, along with the division of the operations, which have a crucial impact on the safety and quality of the finished product.

\begin{tabular}{|c|c|c|c|}
\hline Stage & Operations & $\begin{array}{c}\text { Lower } \\
\text { Specification } \\
\text { Limit (LSL) }\end{array}$ & $\begin{array}{c}\text { Upper } \\
\text { Specification } \\
\text { Limit (USL) }\end{array}$ \\
\hline \multirow{6}{*}{ I } & tub \& forming (measurement 1); & 404,1 & 406,7 \\
\hline & welding front tube; & & \\
\hline & resistance welding; & $>$ & 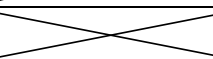 \\
\hline & $\begin{array}{l}\text { riveting elements on the front tube (measurement 2); } \\
\text { (measurement 2); }\end{array}$ & 414,7 & 416,7 \\
\hline & riveting\& flaring (measurement 3); & 30 & 34 \\
\hline & adjustment of the seat plate; & 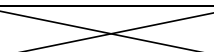 & $>$ \\
\hline \multirow{5}{*}{ II } & varnishing; & $\rightarrow$ & $>$ \\
\hline & springs insertion; & 3 & 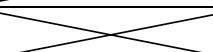 \\
\hline & installation of a lever and handles; & $M$ & $M$ \\
\hline & final folding; & $S$ & $S$ \\
\hline & $\begin{array}{l}\text { verification of security - sliding force survey } \\
\text { (measurement 4). }\end{array}$ & lack & 160 \\
\hline
\end{tabular}

Source: Authors

The Kolmogorov $\lambda$ test, with the amendments of Lilliefors (level of significance $\alpha=0,05$ ) and histograms for the analyzed measurement (Figure 2), show that it is impossible to use conventional control charts for the process of shaping the front tube as well as riveting of the components on the 
front tube, as the measurement data do not reveal a normal distribution. Therefore, these processes will not be accounted for further considerations. Additionally, the histogram for the distribution of rear tube diameters after flaring indicates the measurement errors (histogram with a "hole”).

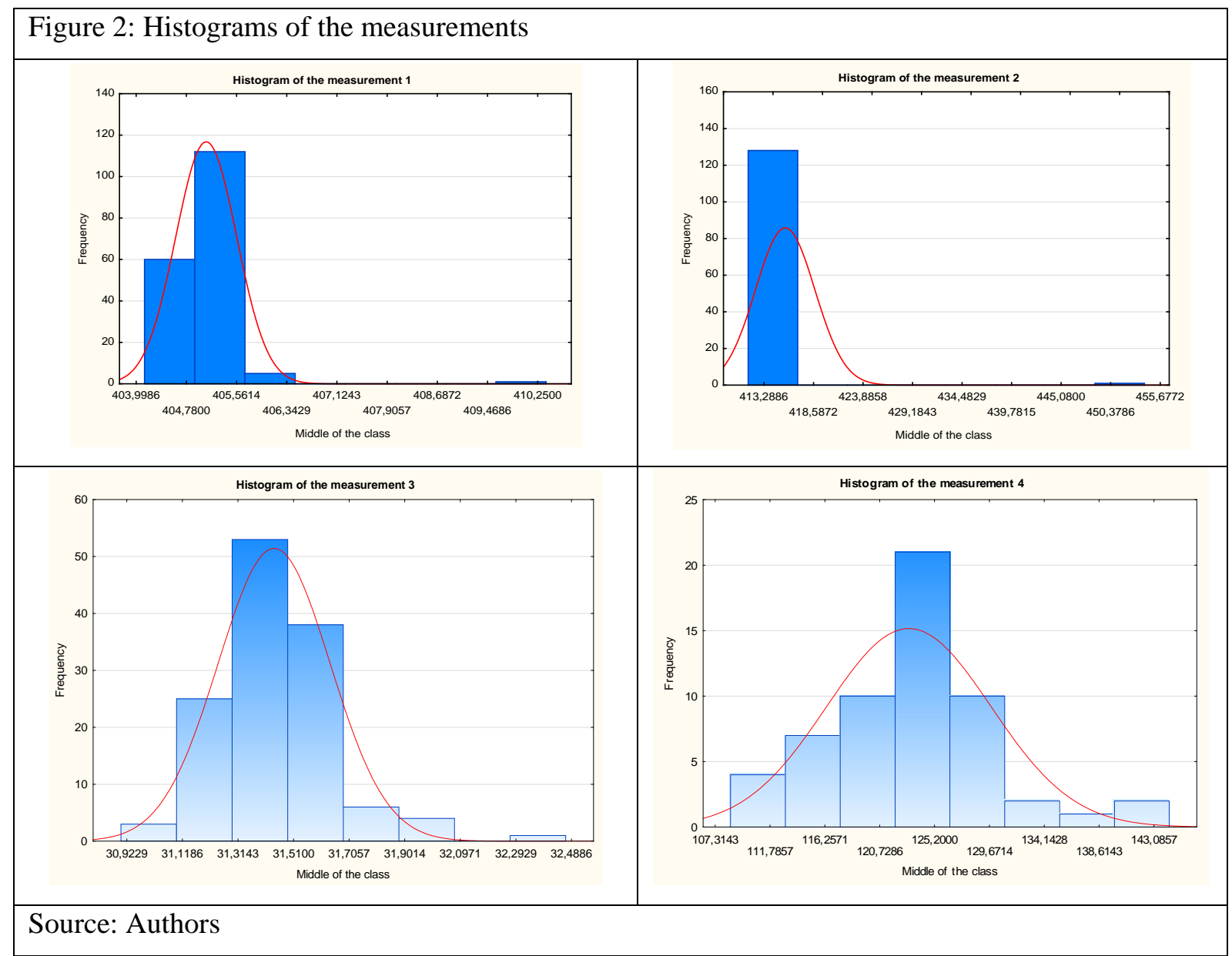

Both rear tube flaring $\left(c_{p}=3,38, c_{p k}=2,44\right)$, as well as the thrust force $\left(c_{p}=\right.$ lack, $\left.c_{p k}=1,83\right)$ show a very good quality capability of the process $\left(c_{p k}>1,66\right)$. Therefore, it is possible to use standard Control Charts for testing the stability of the process in the car seat frame production. Simultaneously, the rear pipe flaring process requires some adjustments due to the failure of establishing it in the middle of the tolerance field $\left(c_{p} \neq c_{p k}\right)$.

The control chart for the measurement 3 (Figure 3) suggests the risk of the maladjustment in the flaring process of the tube rear (which is surprising in view of the high ability of the process). On the IX chart, it was revealed that five measurements exceed or are located at the Upper Control Limit in the following samples: No. 7, 8, 67, 111, and 117. Furthermore, on the MR chart, four measurements (9, 80, 112, and 118) exceed the Upper Control Limit, which indicates sudden jumps of the rear tube diameters after flaring. 


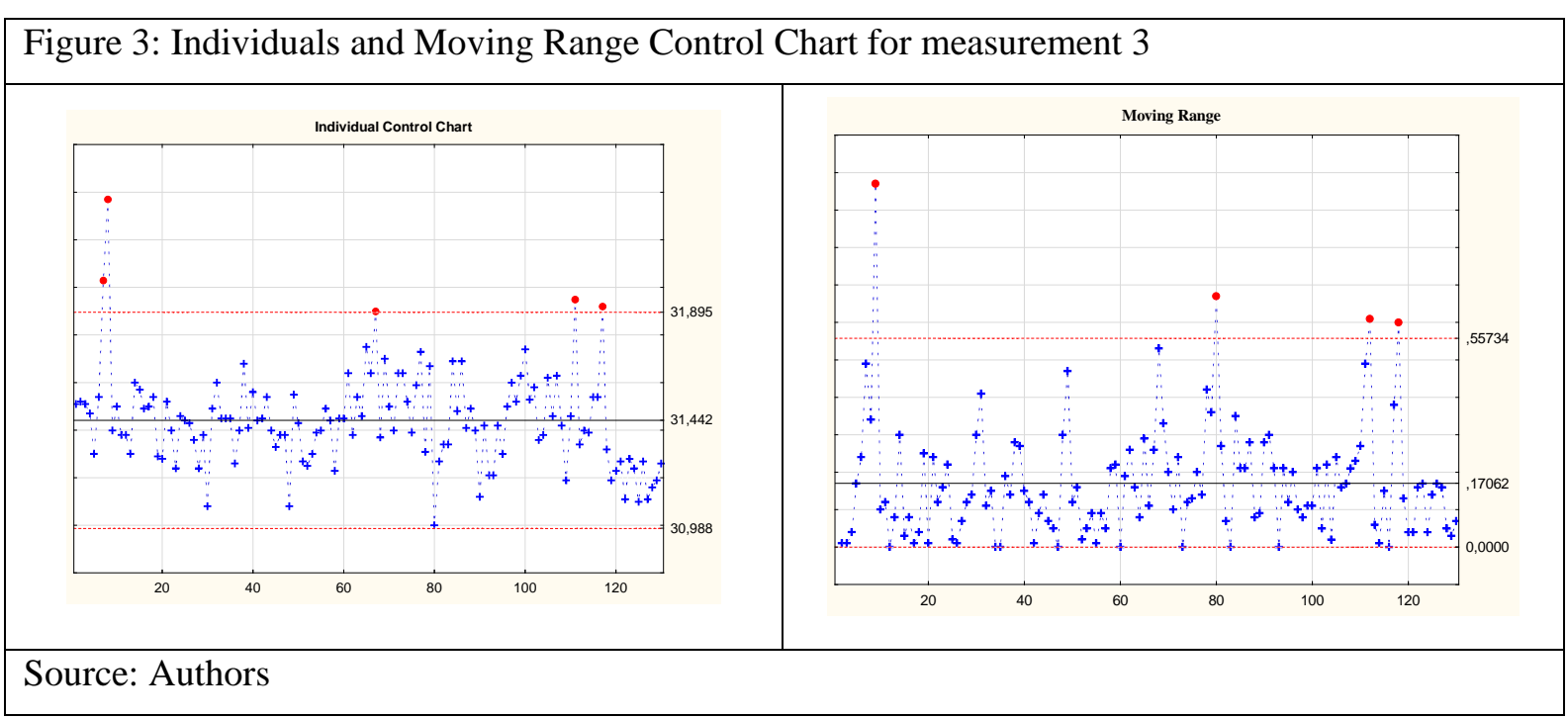

In turn, on the thrust force charts (Figure 4), a single signal appeared, indicating possible disorders in the process (IX and MR measurement: 5 and 6, respectively). It can, therefore, be concluded that the process is statistically adjusted, although one should determine the cause of the appearance of the deviations from the standards.

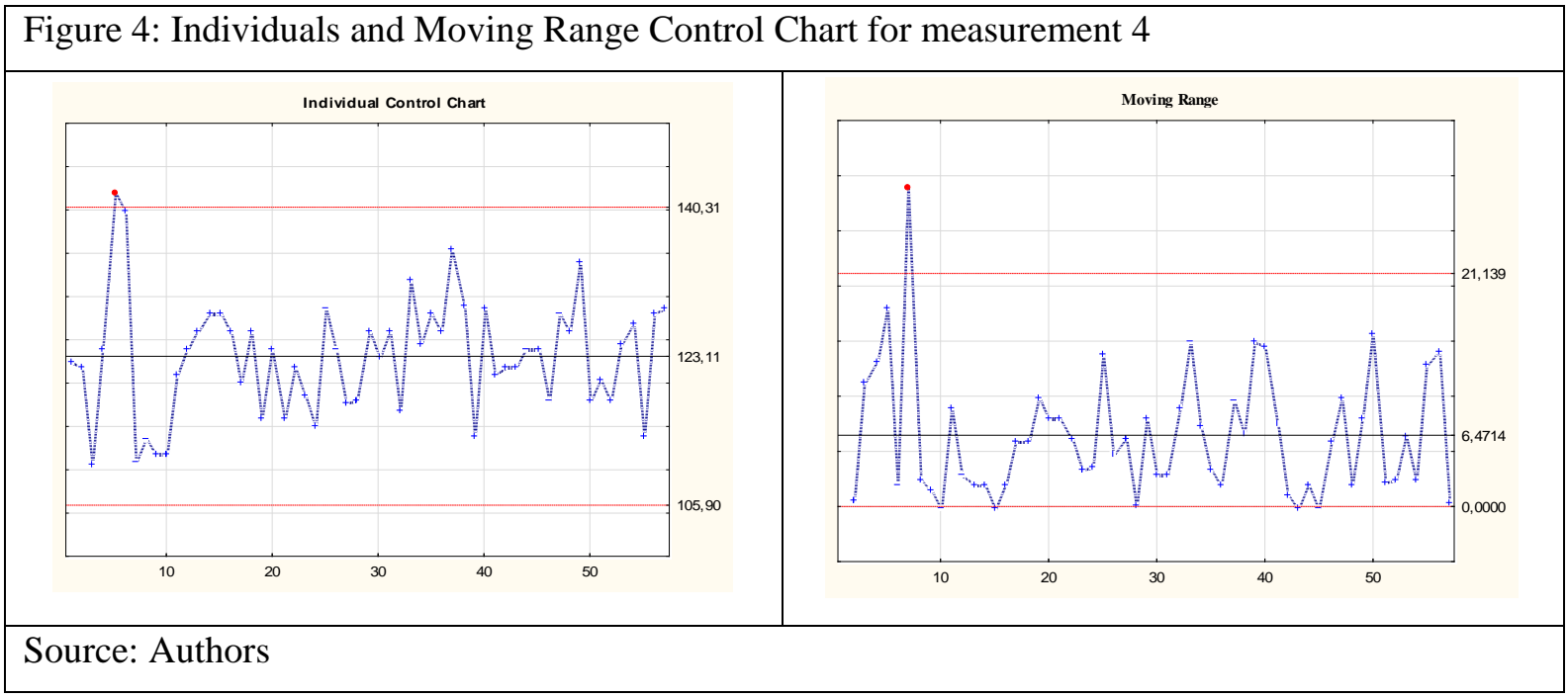

In order to initially analyze the appearance of special causes on the Control Chart (measurement 3), with the use of the three-sigma rule and the confidence ranges for the average, three Gross Errors were identified and removed (observation 8, 7, and 11). Their elimination contributed to the indices improvement of the quality capability of the process (new values are: $c_{p}=3,99, c_{p k}=2,84$ ). It is still, however, required to introduce the process settings adjustments $\left(c_{p} \neq c_{p k}\right)$. The shape of the histogram has also improved (Figure 5), which no longer contains "a hole" and resembles more of a normal distribution. In turn, the control chart contained a reduced number of signals of possible process maladjustment (Figure 5). 


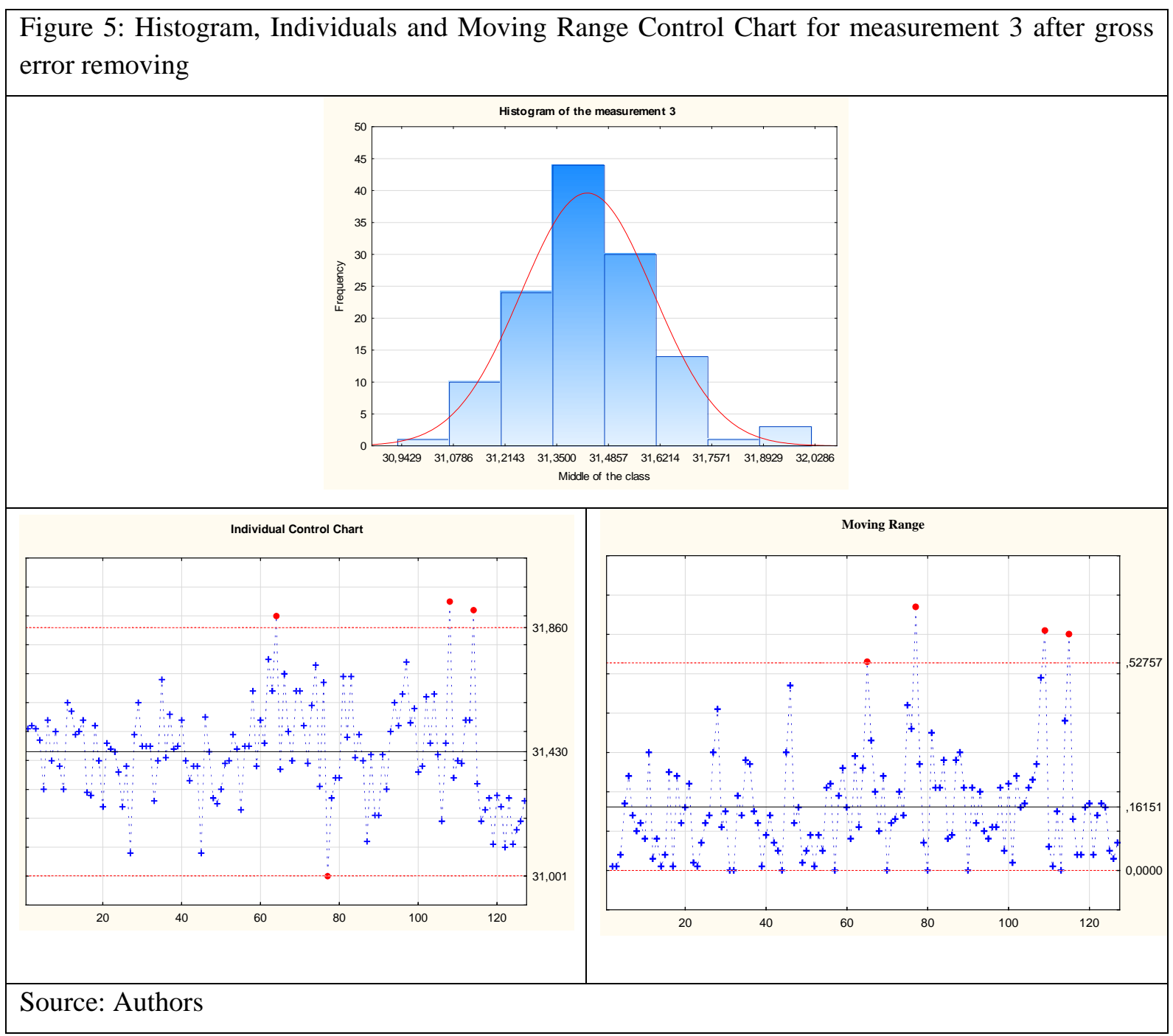

Elimination of Gross Error allowed partial explaination of the reasons why there was an appearance of signals indicating a threat of the rear tube flaring process maladjustment. However, unusual observations appear on the control charts; this requires further and deeper explanation of the reasons of their occurrence—-by a more detailed analysis of the process itself.

\section{Conclusion}

The Statistical Process Control provides many powerful tools, such as the Control Charts that allow continuous monitoring of production processes. An undoubted advantage of the application is the possibility to react quickly against disturbances occurring in the process before, e.g. the number of defective products grows. Such a "preventive policy" allows companies to avoid the additional costs associated with poor quality, e.g. the elimination of the effects of low-quality products.

The analysis carried out in the company, producing car seat frames, indicates that the control charts can issue false signals, suggesting the possibility of the occurrence of the process maladjustment. This is called an "error of the first type," which makes an incorrect inference to the lack of statistical stability when the process is stable. As a result, unnecessary actions are undertaken aiming to introduce corrective measures; consequently, the company is at risk of sustaining unnecessary costs.

Elimination of Gross Errors at the first stage of analysis concerning the causes of disorders in the manufacturing process aims at the identification of false signals at the Control Charts, in which the source may be, for example, improperly made measurements. The above-described procedure turns 
out to be effective, especially when the variability of the particular product physical property indicates the measurement errors (histogram with the "hole").

\section{Acknowledgements}

M. Sc. Izabela Czabak-Górska is a scholarship holder of the Doctoral Scholarships Project - Research Staff Investment in the Voivodeship of Opole II co-financed by the European Union within the European Social Fund.

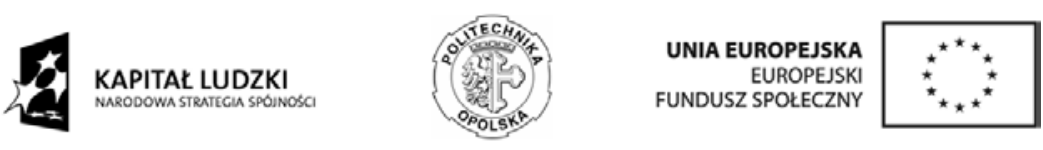

Projekt wspólfinansowany ze środków Europejskiego Funduszu Spolecznego

\section{References}

Aczel, A. D. (2012). Complete Business Statistics. Eight Edition. Wohl Publishing.

Czabak-Górska, I. D., \& Lorenc, M. (2014). Analiza stabilności procesu produkcyjnego - studium przypadku. Logistyka, 6 , 12075 - 12079.

Greber, T. (2000). Statystyczne sterowanie procesami - doskonalenie jakości z pakietem STATISTICA. Kraków: StatSoft.

Jensen, W. A., Jones-Farmer, L. A., Champ, C. W., \& Woodall, W. H. (2006). Efects of Parameter Estimation on Control Chart Properties: A Literature Review. Journal of Quality Technology, 38(4), 349 - 364.

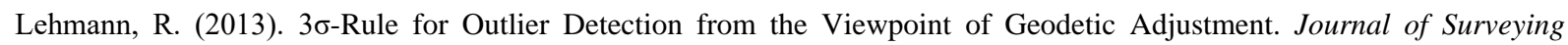
Engineering, 139(4), 157-165.

Narasimhan, S., \& Jordache, C. (2000). Data Reconciliation and Gross Error Detection: An Intelligent Use of Process Data. Houston: Gulf Professional Publishing.

Oakland, J. (2007). Statistical Process Control. Sixth Edition. Butterworth-Heinemann.

Shewhart, W. A. (1931). Economic Control of Quality of Manufactured Product. New York: D. Van Nostrand Company.

Thompson, J. R., Koronacki, J., \& Nieckuła J. (2005). Techniki zarządzania jakościa od Shewharta do metody "Six Sigma" [Quality management techniques from Shewhart to the method of "Six Sigma"]. Warszawa: Akademicka Oficyna Wydawnicza Exit.

Yang, Y., Ten, R., \& Jao, L. (1995). A study of gross error detection and data reconciliation in process industries. Computers \& Chemical Engineering, 19(1), 217-222. 